\title{
A Construção do Plano da Clínica e o Conceito de Transdisciplinaridade
}

\author{
Eduardo Passos ${ }^{1}$ e \\ Regina Benevides de Barros \\ Universidade Federal Fluminense
}

\begin{abstract}
RESUMO - O artigo toma o conceito de transdisciplinaridade para propor um confronto entre as noções de campo e plano da clínica. Após a discussão da utilização do conceito de campo no âmbito da Psicologia, focaliza-se o tema da clínica para pensar sua sintonia com o pensamento contemporâneo. Defende-se a idéia que toda clínica é transdisciplinar, apoiando-se em contribuições teóricas como as da filosofia de Gilles Deleuze e a biologia da autopoiese de Humberto Maturana e Francisco Varela.
\end{abstract}

Palavras-chave: Transdisciplinaridade; Campo; Clínica.

\section{The Clinic Plan's Construction and Transdisciplinarity}

\begin{abstract}
This paper deals with the concept of transdisciplinarity in order to propose a comparison between the notions of "field" and "clinic grounds". After discussing the use of the concept of "field" within Psychology, we focus on the issue of clinic and its tuning with contemporary thinking. The idea that clinic is always transdisciplinary is supported by such theoretical contributions as that of Giles Deleuze's philosophy and Humberto Maturana and Francisco Varela's biology of autopoiesis.
\end{abstract}

Key words: Transdisciplinarity; Field; Clinic Psychology.

Nosso ponto de partida se localiza no desafio de pensar a clínica enquanto transdisciplinar, e tão somente assim concebê-la. Esta afirmação, inicialmente vaga, força-nos a enfrentar a tarefa de depurar os vários sentidos que aí se atravessam.

Para começar, é fundamental que se diga que a construção de uma clínica transdisciplinar deve imediatamente se afastar de qualquer identificação a uma nova técnica, um novo modismo. A direção que se aponta é bem outra: a possibilidade de pensar o campo da clínica nisso que ele tem de potência de se criar e recriar a cada instante.

\section{A noção de campo}

Se falamos em campo da clínica, devemos tomar esta expressão só provisoriamente, partindo do sentido comum como habitualmente nos referimos ao campo de um saber ou campo de uma prática.

A noção de campo, no âmbito da Psicologia, é introduzida pela escola alemã da Gestalt. Com Lewin, as noções de campo e estrutura gestáltica saem do território teóricoexperimental dos estudos cognitivos para assumirem um compromisso tecnológico enquanto um instrumento de modificação de comportamento (Koffka, 1935; Köhler, 1928/1948; Lewin, 1936/1973). Na década de 30, Lewin leva essas idéias da psicologia alemã para os Estados Uni-

1 Endereço: Rua das Laranjeiras, 226/801, Laranjeiras. Rio de Janeiro, RJ. CEP: 22240-001. E-mail: epassos@ antares.com.br dos na tentativa de superar a pré-cientificidade aristotélica do conceito de classe, que sustenta sistemas classificatórios e quantificáveis. Tendo a lei - esta que a Psicologia enunciou tentando garantir seu estatuto científico - caráter estrutural, pois estabelece relações funcionais entre componentes de um sistema, Lewin passa a explicar a ação individual a partir da estrutura que se estabelece entre o indivíduo e seu meio ambiente, num determinado momento. Essa estrutura é um campo dinâmico, campo de forças e que tende ao equilíbrio. Ela compreende a totalidade dos fatos coexistentes e mutuamente interdependentes. Assim como o indivíduo e seu meio ambiente formam um campo psicológico, o grupo e seu ambiente formam um campo social.

Observemos que a idéia de dinâmica consiste em referir o objeto/sujeito ao sistema ou à situação, ou seja, deverse-ia avaliar as forças frenadoras e impulsoras presentes no campo, forças com intensidade e direção variadas. O campo lewiniano é dinâmico porque nele se distribuem valências diferenciadas - de atração ou repulsão, frente às quais se define a posição dos objetos/sujeitos².

Mas a contribuição de Lewin (1936/1973), no que se refere à noção de campo, ganha ainda outros contornos na formulação da proposta de pesquisa-ação, quando diz que

2 O conceito de Strukturiertheit com que trabalha Lewin, em sintonia com a Psicologia da Gestalt, não é incompatível com a idéia de dinâmica. A importância concedida ao Princípio do Equilíbrio (todo sistema tende ao equilíbrio) é correlata, neste autor, à definição dos aspectos dinâmicos da estrutura psíquica (Lewin, 1935/1975). 
o pesquisador está colhido em seu campo de pesquisa. Aí é a questão da objetividade do pesquisador que é destacada como não mais podendo se colocar "fora" do campo investigado. O campo incluía tanto o pesquisador quanto o objeto pesquisado.

A concepção lewiniana, apoiada na perspectiva científico-fisicalista, ratifica a introdução da noção de campo no terreno da Psicologia. Fica claro, entretanto, que ainda permanece a separação entre indivíduo e meio, entre grupo e meio ambiente, etc. Os termos se relacionam, há zonas de interferência entre ambos, mas eles se mantêm enquanto unidades. A quebra maior destas fronteiras talvez tenha se situado no projeto da pesquisa-ação, quando propunha a reunião da teoria e da ação. Aproximemo-nos um pouco mais e acompanhemos o movimento do referido projeto.

A corrente positivista em voga, que acreditava ser possível o pesquisador se manter "fora do campo de investigação", pregava um entrevistador neutro e independente em relação às estruturas de poder da organização estudada, um sociólogo ou psicólogo que deveria fazer tábula rasa de suas experiências anteriores, de seus valores, opiniões ou preconceitos. Ele deveria, em suma, colocar-se como um observador "exterior".

No projeto da pesquisa-ação (Thiollent, 1987; Barbier, 1977/1985) a busca de dados inclui testemunhos, associa entrevistas, questionários, análises de conteúdo e restituição das informações aos pesquisados. O pesquisador se vê como incluído no campo que investiga e sua ação modifica o objeto estudado. Visa, muitas vezes, à tomada de consciência, e os disfuncionamentos são vistos como efeitos de erros (de juízo, de estratégias), efeitos de crises (ação de agentes patógenos) e de descomposturas (deterioração de elementos). A ordem é racional e natural, e a desordem, patológica.

Uma perspectiva socioterapêutica ${ }^{3}$ desenvolve-se a partir das contribuições de Lewin, voltada para as organizações. Buscava examinar as formas de resistência à mudança, estabelecendo relações entre o formal (nível estrutural) e o informal (nível conjuntural). O questionamento se fazia sobre uma análise microorganizacional ${ }^{4}$ que objetivava a otimização do funcionamento social. Em ambas as perspectivas - lewiniana e socioterapêutica - verifica-se o caráter utilitário com que a pesquisa-ação é usada. O pesquisador se via como "agente de mudança" e o privilégio de sua ação era o amadurecimento dos indivíduos através da

3 G. Lapassade (1974/1977), ao falar do nível de intervenção numa organização social, apresenta algumas experiências voltadas para a "facilitação de certas mudanças das relações" estabelecidas no campo do trabalho. Iniciada com Lewin em 1943, quando este atua nos conflitos sociais, logo outras intervenções se sucedem, ora utilizando certos instrumentos de abordagem, ora alterando etapas e procedimentos de ação. É neste sentido que Lapassade chega a nomear de Socioterapia aquelas intervenções em que o psicossociólogo consultor é chamado para facilitar mudanças "um pouco como o psicanalista e, de maneira geral, o psicoterapeuta [que] são especialistas em mudança” (p. 91).

4 A noção de microorganização tem aqui sentido de pequeno, local, resguardando nessa escala menor as propriedades de identidade, totalidade e unidade presentes nas macroestruturas. evolução das relações, conduzindo a uma maior sensibilização e conscientização.

O que podemos perceber é que Lewin, marcado certamente pelo fato de ter se tornado cidadão norte-americano, partilhando dos ideais dessa "democracia capitalista" que valorizava seus estudos em Psicologia Social, rompia com os ditames conservadores que regiam as ciências sociais da época (ao mostrar que o pesquisador era colhido em seu campo de investigação), mas ainda permanecia numa visão dicotomizante no que se refere à relação teoria-prática e à relação sujeito-objeto.

\section{Da pesquisa-ação à pesquisa-intervenção.}

A partir dos anos 60, com a influência tanto da Psicanálise - que valorizava os aspectos inconscientes e a escuta analítica - quanto dos movimentos políticos - que criticavam o centralismo partidário -, a perspectiva conscientizadora da pesquisa-ação passou a ser contestada. O movimento político da década de 60, com sua característica descentralizadora, tem no Maio de 68 uma das expressões da multiplicidade de formas e focos de luta sócio-política. A Grande Recusa, no dizer de Marcuse (1955/1968), apontava para uma crítica disseminada e multifocalizada das formas estabelecidas/instituídas de existência. Era o status quo, em suas mais variadas versões, que era colocado em cheque, inclusive aquele tão bem estabelecido pelo Partido Comunista.

A articulação entre a Psicanálise e os movimentos políticos de esquerda foi um dos resultados, a princípio surpreendente, dos acontecimentos que marcaram o movimento contracultural dos anos 60 . Tomando a situação exemplar de Maio de 68 na França, podemos avaliar como a indisposição inicial da esquerda frente ao freudismo foi se alterando até alcançar tanto uma reconciliação, ou um novo freudo-marxismo, de base estruturalista, quanto o aparecimento de outros híbridos que atravessavam os domínios da clínica e da política (Turkle, 1981). Em 1963, L. Althusser convida J. Lacan a levar seu seminário para a Escola Normal, onde a filosofia marxista se agencia com a Psicanálise graças ao denominador comum do estruturalismo. E se os "comitês de ação", que tomaram para si a tarefa de ser a forma embrionária da "nova sociedade revolucionária", pichavam slogans antipsicanalíticos e antiestruturalistas na Paris de 68, ao final do movimento se aceitava que cabia buscar explicação sobre o fracasso da revolução nas produções inconscientes da subjetividade. A força iconoclastra de Lacan (1966/1978), a partir dos anos 50, sobretudo seu antiamericanismo (na forma de seus ataques à Psicologia do Ego) e seu antiinstitucionalismo (na forma de suas lutas com as sociedades psicanalíticas) permitiram que o determinismo da concepção estruturalista de inconsciente fosse progressivamente tolerado, apesar de sua impossível conciliação com noções tão defendidas naquele momento político, como as de liberdade e autonomia. Mas se as condições objetivas e materiais estavam garantidas, como explicar o fracasso da revolução? Repetia-se a mesma indagação que na década de 20 motivou as reflexões dos marxistas da escola frankfurtiana, perplexos 
com os resultados da crise do capitalismo de 1914-1919. Assim como os frankfurtianos privilegiaram o estudo do fenômeno da alienação (conceito limite entre materialismo histórico e a Psicologia), uma nova aliança entre Marx e Freud garantiu o cruzamento entre a Psicanálise e a Política nos anos 60, o que gerou outros efeitos que a Psicanálise, ela mesma, teve e ainda tem dificuldade de absorver.

Neste contexto, onde se atravessam clínica e política, pesquisa e ação, a palavra intervenção se junta à pesquisa, não para substituir a ação, mas para produzir outra relação entre teoria e prática, assim como entre sujeito e objeto. É com o movimento institucionalista ${ }^{5}$, incrementado a partir de meados de 60 , que a corrente psicossociológica americana será criticada. Isto se deu tanto no âmbito da Sociologia, que, recusando sua vertente abstrata, se fez intervenção, como no da Psicologia em seus vários âmbitos (educativo, terapêutico, do trabalho), que passou a recusar a psicologização dos conflitos .

A Análise Institucional Socioanalítica, corrente desenvolvida na França durante as décadas de 60/70, vai então formular a idéia de uma pesquisa-intervenção que visava a interrogar os diversos sentidos cristalizados nas instituições. Tratava-se de produzir evidências que visibilizassem o jogo de interesses e de poder encontrados no campo de investigação. Sua metodologia estava baseada, portanto, numa argüição que desmanchasse os territórios constituídos e convocasse a criação de outras instituições. É claro que a própria noção de instituição é modificada, já que, ao não ser identificada à de estabelecimento, remete ao processo de produção constante de modos de legitimação das práticas sociais.

A intervenção estará associada à construção e/ou utilização de "analisadores", conceito-ferramenta formulado por Guattari ${ }^{6}$, no contexto da Psicoterapia Institucional, que veio a ser incorporado pela Socioanálise. Os analisadores seriam acontecimentos - no sentido daquilo que produz rupturas, que catalisa fluxos, que produz análise, que decompõe. Eles assinalam as múltiplas relações que compõem o campo tanto em seu nível de intervenção quanto em seu nível de análise. O nível de intervenção se caracteriza pela definição de um território a partir da encomenda endereçada a alguém, em geral a um especialista. Isto inclui não apenas como o pedido é formulado mas também o encargo social que lhe é inseparável, isto é, os processos historicamente produzidos de legitimação do exercício de uma tal função. Já o nível de análise aponta para as virtualidades presentes a partir da intervenção, dominantemente submetidas ao encargo social, às vezes delineando linhas de fuga (Rodrigues, 1992).

$5 \mathrm{O}$ movimento institucionalista refere-se, aqui, às correntes da Psicoterapia Institucional, tanto em sua versão Tosquelliana, quanto na versão Guattari - J. Oury, bem como às correntes da Pedagogia Institucional - versão Fonvieille - e versão Aida Vasquez- F. Oury. Destaque-se a corrente da Socioanálise de Lourau - Lapassade que, no Brasil, passou a ser mais identificada como "Análise Institucional". (Rodrigues, 1994).

6 O conceito de analisador é apresentado em textos de F. Guattari publicados isoladamente entre 1953 e 1969 e reunidos posteriormente no livro Psychanalyse et Transversalité. (Guattari, 1972).
Esta nova posição de análise se caracteriza, portanto, por um processo de desnaturalização permanente das instituições, incluindo a própria instituição da análise (aqui entendida como atividade de um "analisador") e a da pesquisa. É neste sentido que a implicação do pesquisador, já anunciada na pesquisa-ação, se modifica. O que Lewin (1936/ 1973) apontava, então, era para a presença dos aspectos afetivo/libidinais do pesquisador na investigação. A noção de implicação, trabalhada pelos analistas institucionais, não se resume a uma questão de vontade, de decisão consciente do pesquisador. Ela inclui uma análise do sistema de lugares, o assinalamento do lugar que ocupa o pesquisador, daquele que ele busca ocupar e do que lhe é designado ocupar, enquanto especialista, com os riscos que isto implica.

Melhor seria dizer, então, análise das implicações, posto que implicado sempre se está. Aquilo para o que as correntes institucionalistas chamam a atenção é a necessidade da análise das implicações com as instituições em jogo numa determinada situação. A recusa da neutralidade do analista/pesquisador procura romper, dessa forma, as barreiras entre sujeito que conhece e objeto a ser conhecido.

As metodologias que utilizam o questionário/entrevista como técnicas fidedignas criam a ilusão de que o pensamento de cada um pode ser "agarrado" na coleta de dados. A expectativa é de objetividade e organização dos problemas. A crença é a de que se melhor apreende a realidade quanto mais versões se acumulem sobre ela. Tais pressupostos mantêm, de todo modo, o objeto como algo a ser apreendido, apreensão garantida pela estrutura $a$ priori do fenômeno que se quer conhecer. A pesquisa-intervenção, ou apenas a intervenção, como procedimento de aproximação com o campo, mostra-nos que ambos - pesquisador e pesquisado, ou seja sujeito e objeto do conhecimento - se constituem no mesmo momento, no mesmo processo.

Como vimos, a pesquisa-ação "articula" pesquisador e campo de pesquisa, portanto, sujeito e objeto, mas ainda os mantém como dois pólos de uma relação.

Se em Lewin (1936/1973) a gênese social do objeto da pesquisa precede à gênese teórica e metodológica, na proposta da Análise Institucional gênese teórica e social são indissociáveis. Aí o momento da pesquisa é o momento da produção teórica e, sobretudo, de produção do objeto e daquele que conhece; o momento da pesquisa é momento de intervenção, já que sempre se está implicado. Se podemos assinalar um caráter utilitário na pesquisa-ação em sua versão praxiológica, a pesquisa-intervenção tem como mote o questionamento do "sentido" da ação.

Um outro aspecto importante a se ressaltar na pesquisaação é seu objetivo de "mudança de comportamento", mudança entendida como chegada a um determinado resultado previamente definido. Já na pesquisa-intervenção o que interessa são os "movimentos", as "metamorfoses", não definidas a partir de um ponto de origem e um alvo a ser atingido, mas como processos de diferenciação. O que estamos marcando como contraste entre as perspectivas é o aspecto global inerente à proposta de mudança, já que, quando se priorizam os movimentos, os processos, é a expressão singu- 
lar que entra em jogo, através, especialmente, da análise das implicações. Não há mais aqui sujeito e objeto, mas processos de subjetivação e de objetivação, criação de planos que ao mesmo tempo criam sujeitos/objetos, que se revezam.

Na pesquisa-intervenção, conforme a entendemos, é sua dimensão de produção que compromete, inicialmente, a dicotomia sujeito-objeto. Nesta mesma direção, um outro dualismo é abalado quando se afirma o caráter de criação da intervenção, pois as noções de teoria e prática são necessariamente reequacionadas. Tradicionalmente, o momento teórico do conhecimento refere-se à construção lógica de um sistema de inteligibilidade para o objeto, e o momento técnico diz respeito à intervenção prática sobre o objeto $^{7}$. Em se apostando no caráter sempre intervencionista do conhecimento, em qualquer de seus momentos todo conhecer é um fazer.

\section{O conceito de transdisciplinaridade}

Podemos, agora, retomar nossa afirmação inicial que concebia a clínica como um campo. Devemos, então, reconsiderar esta afirmação contando com o reequacionamento da relação sujeito-objeto e o redirecionamento da relação teoria-prática. Tanto num quanto noutro aspecto o que se vê ruir é a idéia de identidade/unidade.

A noção de campo começa a experimentar um deslocamento de seu sentido habitual quando é apontado o engendramento dos termos que lhe balizariam os limites. Sujeito e objeto não são mais realidades previamente dadas, mas se produzem por efeito das práticas. Estas, sejam teóricas ou não, devem explicar as posições subjetivas e objetivas que tendem a se estabilizar como realidade. Nessa perspectiva, já não se pode mais admitir sujeitos determinando formas de conhecer objetos, nem objetos com suas bem marcadas linhas se dando a conhecer aos sujeitos.

Mas precisamos avançar mais em nossas formulações para que possamos radicalizar nossa afirmação inicial de que a clínica só pode ser concebida como transdisciplinar.

Neste ponto temos que tomar em análise as disciplinas que vêm marcando fronteiras muitas vezes rígidas na definição de seus objetos de pesquisa e/ou interesse.

Em que pese o esforço observado nas últimas quatro décadas de se flexibilizar tais fronteiras, o mais que se conseguiu, no melhor dos casos, foi se estabelecer um diálogo entre profissionais mais identificados com tal ou qual disciplina, remetidos, na maior parte das vezes, a determinados especialismos.

Esta flexibilização se realiza através de diferentes procedimentos: o movimento de disciplinas que se somam na tarefa de dar conta de um objeto que, pela sua natureza multifacetada, exigiria diferentes olhares (multidisciplinaridade), ou, de outra forma, o movimento de criação de uma zona de interseção entre elas, para a qual um objeto

7 Lembremos da etimologia das palavras: teoria, derivando do grego theoria "ação de contemplar, examinar"; e técnica, derivando do grego techné "fazer". específico seria designado (interdisciplinaridade). Mas o que vemos como efeito, seja da multidisciplinaridade, seja da interdisciplinaridade, é a manutenção das fronteiras disciplinares, dos objetos e, especialmente, dos sujeitos desses saberes.

Tomemos como exemplo o caso dos grupos, para avançarmos um pouco mais em nossa análise.

Fernández e De Brasi (1993) apontam, através da idéia de campo grupal, para uma almejada superação da "velha dicotomia sujeito-objeto". Entretanto, mesmo nestes autores, a argumentação não chega à ruptura almejada da dicotomia sujeito-objeto e da dualidade indivíduo-sociedade. O que nos apontam Fernández e De Brasi? Dizem:

Campo [grupal] e não objeto [grupo]. Multiplicidade nas visadas, nas intervenções e nos saberes. Entrecruzamentos nos atos e discursos. Campo que resgata o diverso como aquilo que agrupa o descontínuo sem cultivar o homogêneo... Campo, então, que não é outro que o do camponês...Metáfora que conecta, mais além de si mesma, ao ser humano com a natureza num clima social-histórico e discursivo particular $e$ irrepetível... (Fernandéz \& De Brasi, 1993, p. 15).

Percebe-se que as formulações dos autores trazem uma crítica ao dualismo sujeito-objeto quando se referem ao campo como entrecruzamento de atos e discursos ou quando metaforizam, ligando-o ao campo do camponês (ligação natureza-cultura, embora ainda dualizada...). Entretanto, o que propõem é uma articulação entre os termos, mantendo-os, de todo modo, como unidades que guardam suas identidades. Aqui os termos continuam vindo antes da relação que estabelecem. São condições a priori a partir das quais o entrecruzamento se faz. $\mathrm{O}$ cuidado que temos que ter é o de não se substituir simplesmente a noção de campo pela de objeto já que assim a oposição entre os termos é mantida só que, desta vez, com um certo grau de articulação.

Para nós, romper com as dicotomias sujeito-objeto, indivíduo-sociedade, natureza-cultura implicaria a constituição de planos onde, ao mesmo tempo, sujeitos-objetos adviriam. Neste caso, o que vem primeiro é a relação, esta sim constituidora dos termos. A noção de campo, é claro, pode ser assim entendida, desde que se tenha o cuidado de não a tornar equivalente a um espaço de articulação entre sujeitos, entre objetos ou entre sujeitos e objetos. Neste caso, cairíamos na noção de intersubjetividade, seja de sistema de objetos ou de "espaço vital" tos independentes em contato uns com os outros.

Como ainda conservarmos a noção de campo quando queremos apontar para o processo de produção que aí se dá? Pois se no movimento do institucionalismo, em suas diferentes vertentes, como apresentamos até então, a noção

8 Lewin (1936/1973) define assim sua noção de espaço vital: A totalidade de fatos que determinam o comportamento de um indivíduo num certo momento. O espaço vital (E) representa a totalidade de possíveis eventos. $O$ espaço vital inclui a pessoa $(P)$ e o ambiente $(A) . C=f(E)=f(P, A)$. Pode-se ser representado por um espaço finitamente estruturado (p. 242). 
de campo aparece e é posta ela também em análise, em uma perspectiva mais panorâmica - que talvez possamos dizer histórico-epistemológica - a questão se recoloca quando somos levados a discutir o que seria a identidade do saber psicológico ou o território geral do campo da Psicologia.

\section{O advento da Psicologia como um campo}

É em um campo que estaríamos implicados em nossas práticas psicológicas. E estamos freqüentemente tão engajados nele que já não poderíamos discriminar as forças que o constituem, ao mesmo tempo que nele somos constituídos como uma de suas partes integrantes. E do que partimos quando nos engajamos neste campo? Sem dúvida, há um enorme poder de sedução neste objeto que se designa como próprio do campo da Psicologia, o que pode nos tornar devotos dele e alheios ao que se arma à sua volta. Digamos então logo do que se trata: do homem diante de sua própria contradição. Eis aí o que nele apela, exercendo esta atração reflexiva que faz com que se indague sobre sua própria condição. Pois o que atrai é o que nele não se resolve, mantendo-se como incompletude ou como uma abertura constituinte, através da qual a condição humana se configura a um só tempo como marcada pela crise e fortalecida pela atitude crítica.

Foucault (1957/1990), em um texto de juventude - e freqüentemente nos esquecemos que na década de 50 suas preocupações eram de psicólogo, comprometido com a história deste saber -, conclui que, orientada pelo ideal de rigor e objetividade das ciências naturais, a Psicologia é levada a renunciar a seus postulados na medida em que reconhece em seu objeto outra coisa diferente da objetividade natural, sendo forçada, então, a utilizar-se de outros procedimentos e métodos de investigação. E se o homem não pode ser tão facilmente localizado na ordem natural, o ideal de precisão, determinismo e previsibilidade já não se sustenta. Daí a necessidade de "renovação total", o que impõe, desde cedo, à Psicologia, uma condição crítica crítica no duplo sentido da palavra: como atividade de crítica e como situação de crise que submete este campo a um equilíbrio instável. Essa renovação é um fato histórico que se repete no desenvolvimento da Psicologia, embora se mantenha como uma tarefa sempre incompleta. E o que parece distinguir este saber é isto que à primeira vista aparenta ser uma correspondência entre a incompletude do seu campo e a incompletude do próprio objeto. Correspondência que, na verdade, só oculta uma relação mais específica e de dupla determinação entre estes termos.

Buscando aproximar-se das ciências naturais, a Psicologia revelou sua particularidade. Pois enquanto aquelas ciências apenas respondem aos problemas postos pelas dificuldades práticas encaradas como limites provisórios de sua experimentação, a Psicologia nasce "neste ponto onde a prática do homem reencontra sua própria contradição" (Foucault, 1957/1990, p. 161). Dotado de uma capacidade de desenvolvimento, o homem experimenta paradas, blo- queios na sua evolução. Dotado de uma memória, inteligência, linguagem, o homem se esquece, erra, tropeça nas palavras. A Psicologia nasce, portanto, como análise deste objeto marcado por uma tensão constituinte, já que nele é impreciso o limite entre o normal e o patológico, o adaptado e o desadaptado, o corpo e o espírito?.

Mas não é tão fácil assumirmos esta estranha condição de nosso objeto. Verifica-se a tentativa, historicamente hegemônica, de resolução da crise subjetiva, tomando-se como meta a ser alcançada o estado de normalidade, de adaptação. Daí uma Psicologia que reduz a contradição da natureza humana a um dualismo, em que um dos pólos é privilegiado como promessa de solução ou apaziguamento da tensão subjetiva. E o que parece sustentar este procedimento, que foucaultianamente chamaríamos de "ortopédico", é a crença inabalável na "natureza humana". É esta natureza que orienta as atitudes corretivas e adaptadoras, e que faz da tarefa psi o mero atendimento de uma demanda inquestionável.

O campo da Psicologia se constitui neste esforço sempre renegociado de superação do naturalismo (Passos, 1994). Pois não basta ter colocado em questão o imperativo metodológico importado das ciências naturais, uma vez que o pressuposto naturalista pode persistir sob outras formas. E desta maneira mantêm-se as antigas fronteiras deste campo, salvaguardando-se, em contrapartida, a identidade de seu objeto. Na verdade, a noção mesma de campo não se preserva quando criticamos radicalmente o naturalismo da Psicologia.

Quando empregamos a noção de campo epistemológico não podemos evitar o ideal de unidade, autonomia racional e progresso que tradicionalmente caracteriza as regiões da ciência ${ }^{10}$. A expectativa de que a ciência se constitua como uma identidade regional faz com que a Psicologia se retraia frente a impossibilidade de alcançar este ideal. Sabemos que a dispersão teórico-tecnológica sempre marcou a história dos estudos psicológicos. Mais como um arquipélago do que como um continente, este saber nunca se firmou em um campo coeso.

Ao contrário, desde o início, três linhas evolutivas se rivalizaram na disputa pela hegemonia neste campo: os estudos do sujeito do conhecimento evoluíram desde a segunda metade do século XIX, definindo uma vertente comprometida com o tema dos processos cognitivos. Contemporânea a esta linha evolutiva, outra se traça apoiada nas práticas clínicas e tendo como tema central o sujeito do desejo

9 Esta idéia presente em Foucault deve-se, sem dúvida, à influência, em sua juventude, exercida por Canguilhem. A epistemologia das ciências da vida construída por este filósofo marcou decisivamente a maneira como Foucault formulou o seu problema inicial. A problematização do objeto da Psicologia - que acreditamos oferecer as bases para as futuras investigações arqueológica e genealógica da obra foucaultiana — é tributária da tese de 1943, Ensaio sobre alguns problemas relativos ao normal e o patológico (Ganguilhem, 1966/1978). Acerca da relação Foucault/Canguilhem, conferir Macherey, (1993).

10 Conferir a noção bachelardiana de "racionalismos regionais". (Bachelard, 1949/1986). 
e do inconsciente. Sem deixar de forjar os seus próprios instrumentos com uma preocupação eminentemente utilitária, as psicotécnicas se desenvolveram voltadas para instituições como a escola, a fábrica e o hospital geral. São, portanto, linhas evolutivas que tenderam a correr paralelamente. E, se é constrangedor este estado de dispersão, é porque se espera do campo uma identidade que reflita aquela de seu objeto. Vemos que o eixo de sustentação de um campo epistemológico é, em última instância, a relação estabelecida entre sujeito e objeto do conhecimento. A especificidade desta relação é que distingue os campos, que define as fronteiras epistemológicas, que delimita as disciplinas (Passos, 1995).

\section{Transdisciplinaridade e clínica}

Mas é exatamente a estabilidade desta relação que, contemporaneamente, criticamos. Podemos chamar esta atitude crítica de transdisciplinaridade, já que os limites entre as disciplinas é perturbado quando se coloca em questão as identidades do sujeito que conhece e do objeto conhecido. A noção de transdisciplinaridade subverte o eixo de sustentação dos campos epistemológicos, graças ao efeito de desestabilização tanto da dicotomia sujeito/objeto quanto da unidade das disciplinas e dos especialismos.

Identificamos, na atualidade, um "construtivismo radical" (Watzlawick, 1981/1994) que não se limita a afirmar que o objeto do conhecimento é histórica e regionalmente constituído. A afirmação da inexistência de uma garantia ou fundamento último para o conhecimento dá a medida da radicalidade desta posição. Pois não só o objeto é construído, mas o sujeito e o sistema teórico ou conceitual com o qual ele se identifica, eles também, são efeito emergente de um plano de constituição que não se pode dizer ter a unidade e homogeneidade de uma disciplina ou do campo científico, já que é composto de materiais heteróclitos, de diferentes gêneros. Há componentes teóricos e tecnológicos, mas também estéticos, éticos, econômicos, políticos e afetivos que se atravessam neste plano, impulsionando seu mecanismo de produção de realidade, seja ela objetiva ou subjetiva ${ }^{11}$. Esta idéia, podemos encontrá-la nos estudos epistemológicos contemporâneos, que ganham o impulso de uma geração de pesquisadores dedicados a pensar a "invenção" dos procedimentos de verdade e objetividade das ciências naturais (Stengers, 1990; 1993; Latour, 1991/1994). O caráter inventivo ou construtivo que se atribui agora às ciências atesta que se deve menos buscar seu fundamento do que traçar o mapa de sua constituição, dando conta dos diferentes "interesses" e componentes que participam da formação dos saberes. Com Stengers, podemos então dizer que, no lugar de buscar o fundamento das ciências, devemos localizar sua fundação: "a fundação

11 A noção de plano de imanência formulada por Deleuze e Guattari permite uma boa apreensão desta dinâmica de produção de realidade a que nos referimos. (Deleuze \& Guattari, 1991; 1980/1997). concerne ao solo e mostra como alguma coisa se estabelece sobre este solo, ocupa-o e o possui; mas o fundamento vem antes do céu, vai do cume às fundações (...)" (Stengers, 1993, p. 82).

A ciência possui uma fundação tal como qualquer outra forma de conhecimento, não se distinguindo por uma pureza ou soberania que transcenda ao mundo sobre o qual ela produz os seus efeitos de verdade e de objetividade. É neste sentido que podemos dizer que o conhecimento é uma forma de implicação e de interferência que é ativa na produção tanto do seu objeto quanto do sujeito de um determinado saber ou especialismo. Estes dois termos (sujeito/objeto) não explicam o processo cognitivo, mas devem antes ser explicados por ele. $\mathrm{O}$ emergentismo de que falamos este que afirma a situação paradoxal do ato cognitivo que engendra seus pólos subjetivo e objetivo - deriva das formulações da Biologia do Conhecimento ou Teoria da Autopoiese de Humberto Maturana e Francisco Varela, representantes de uma fase recente das ciências cognitivas que trabalham com a noção de sistemas cognitivos operacionalmente fechados e em rede. O impacto da Teoria da Autopoiese nos estudos da cognição se deve muito à sua recusa do modelo da representação. Para estes autores, conhecer não é representar, como se supõe em uma perspectiva que toma a cognição como processamento da informação transferida do meio para o organismo. Ao contrário, o organismo e, mais especificamente, o sistema nervoso, é concebido como um sistema em rede fechada. A noção de "clausura operacional" busca dar conta desse funcionamento de uma rede que é espacialmente fechada (fechada informacionalmente, não sendo um sistema input), embora aberta temporalmente, já que em constante modificação de sua estrutura ao longo de uma " deriva natural". (Maturana \& Varela, 1980).

Nesta perspectiva, a noção de rede se torna central já que permite pensar uma mecânica de conexão de elementos pré-individuais ${ }^{12}$ e sub-simbólicos que produz como efeito emergente o mundo individuado: "todo ato de conhecer produz um mundo (...) todo fazer é conhecer e todo conhecer é fazer" (Maturana \& Varela, 1987/1995). Conclui-se que, em se assumindo este construtivismo radical, já não podemos nos contentar com uma explicação do conhecimento assentada no idealismo (fundamento no sujeito cognoscente) ou no realismo (fundamento no objeto do conhecimento). Pois se o ato de conhecer engendra os pólos de sua relação, devemos aceitar que este ato é sem fundamento ou, como prefere Varela, uma "enação"13.

No lugar de campo epistemológico pensamos então em um plano de constituições ou de emergências a partir do

12 Em Simondon (1989) esta noção de processo de produção de realidade é apresentada com o conceito de "individuação". Segundo esse autor, preocupado com a gênese dos indivíduos, individuação é a "resolução parcial e relativa que se manifesta em um sistema que encerra potenciais e mantém uma certa incompatibilidade por relação a si mesmo, incompatibilidade feita de forças de tensão como também de impossibilidade de uma interação entre termos de dimensões extremas" (p. 12). 
qual toda realidade se constrói, desfazendo-se qualquer ponto fixo ou base de sustentação da experiência. O conhecimento científico não escapa desta mecânica, estando ele também constituído sem fundamento substancial, sem natureza mantenedora da sua neutralidade e objetividade. Não podemos, doravante, aceitar a pretensão de um conhecimento desinteressado que apenas desvela a realidade de seu objeto. Pois conhecer é estar em um engajamento produtivo da realidade conhecida, mas também é constituir-se neste engajamento por um efeito de retroação, já que não estamos imunes ao que conhecemos. Sujeito e objeto se engendram no ato de conhecimento, não restando nenhuma anterioridade, nenhuma garantia prévia. Em sendo assim, como nortear nossas escolhas teóricas? Como distinguir os conceitos? Paira sobre nós a ameaça do relativismo, que constantemente devemos expurgar. Pois quando abandonamos as garantias do fundamento, o pensamento corre o risco de se perder na indiferença e no relativismo, como se tudo ou nada valesse. É em reação a esta ameaça que devemos afirmar nossas escolhas conceituais e definir nossas posições críticas.

Não há indiferença no trabalho com os conceitos quando sabemos que são operadores de realidade. Neste sentido, eles nos chegam como ferramentas. Um conceito-ferramenta é aquele que está cheio de força crítica. Ele está, portanto, cheio de força para produzir crise, desestabilizar. É assim que entendemos a idéia de "intercessor" (Deleuze, 1990/1992). O conceito é um intercessor quando é capaz de produzir tal tipo de efeito.

Vale aqui uma diferença radical das noções de interseção e intercessão. No primeiro caso, a relação é de conjugação de dois domínios na constituição de um terceiro, que se espera estável, idêntico a si e para o qual pode-se definir um objeto próprio. É o caso, como acima apontado, da interdisciplinaridade. No segundo, que é o caso da transdisciplinaridade, a relação que se estabelece entre os termos que se intercedem é de interferência, de intervenção através do atravessamento desestabilizador de um domínio qualquer (disciplinar, conceitual, artístico, sócio-político, etc.) sobre outro. Na interdisciplinaridade, portanto, temos a gênese de uma nova identidade, enquanto na transdisciplinaridade temos um processo de diferenciação que não tende à estabilidade.

Em seu movimento de intercessão os conceitos são imediatamente ferramentas, porque se constróem num certo regime de forças. Não são abstratos, não são dados, não são preexistentes. Eles compõem, o tempo todo, um sistema aberto relacionado a circunstâncias, e não mais a essências. É por isso que dizemos que precisamos inventar conceitos, criar conceitos que tenham necessidade. Cada conceito se relaciona a um determinado conjunto de forças,

13 “O mundo não é algo que nos é dado, mas é alguma coisa em que temos parte graças ao modo como nos movemos, tocamos, respiramos e comemos. Eis o que chamo de cognição como enação, partindo das conotações semânticas do termo 'enação' que sugerem o fazer emergir mediante a manipulação concreta" (Varela, 1992/1995, p. 18). ele é parte de um plano onde fluxos diversos se atravessam. $\mathrm{O}$ que se pode fazer em relação a um determinado conceito é percorrer suas linhas de constituição, as relações que foi estabelecendo com as variações dos movimentos.

Os intercessores, como bem já nos apontou Deleuze (1990/1992), interessam-nos pelos movimentos, não pelo que se passa antes deles, ou pelo que os causa, mas pelo que se dá "entre", pelo que está se dando. Como figuras híbridas que se põem a operar pelo entrecruzamento de diferentes domínios, os intercessores não podem ser pensados fora da relação de interferência que se produz entre domínios (tal como o intercessor guerra mundial cruzando a história do cinema e produzindo o efeito de desestabilização da narrativa fílmica com as imagens sem reação do neorealismo italiano). Compreende-se, portanto, que o intercessor é uma noção funcionalista cujo sentido não pode ser apreendido senão no interior de uma certa operação operação de encontro, contágio, cruzamento que desestabiliza e faz diferir. Por isso, trata-se de uma noção refratária às definições abstratas. Não basta pôr os conceitos a se mover, é necessário criá-los.

Se o objeto da ciência é criar funções, o da arte criar agregados sensíveis e o da filosofia criar conceitos, Deleuze (1990/1992) pergunta: como é possível que um conceito, um agregado sensível e uma função se encontrem? Os exemplos de que lança mão nos indicam que filosofia, arte e ciência entram em relação de ressonância, de troca mútua. Mas o que se troca, aqui, não são informações ou comandos. Fazer variar um certo domínio por interferência de um outro, tal como a clínica pode sofrer o intercessor artístico, não é imitar ou repetir, em um outro sistema, o que foi importado. A relação de intercessão é uma relação de perturbação, e não de troca de conteúdos. Embarca-se na onda, ou aproveita-se a potência de diferir do outro para expressar sua própria diferença. Deleuze diz: "Uma disciplina que se desse por missão seguir um movimento criador vindo de outro lugar abandonaria ela mesma todo papel criador...” (p. 156) .

Aqui a noção de transdisciplinaridade vai ganhando novos contornos. Não se trata de abandonar o movimento criador de cada disciplina, mas de fabricar intercessores, fazer série, agenciar, interferir. Frente às ficções preestabelecidas, opor o discurso que se faz com os intercessores. Não uma verdade a ser preservada e/ou descoberta, mas que deverá ser criada a cada novo domínio. Os intercessores se fazem, então, em torno dos movimentos, esta é a aliança possível de ser construída quando falamos de transdisciplinaridade, quando falamos de clínica.

Problematizar os limites de cada disciplina é argüi-la em seus pontos de congelamento e universalidade. Tratarse-ia, nesta perspectiva transdisciplinar, de nomadizar as fronteiras, torná-las instáveis. Caotizar os campos, desestabilizando-os ao ponto de fazer deles planos de criação de outros objetos-sujeitos, é a aposta transdisciplinar.

Assim se apresenta a clínica, para nós. O que nos interessa são modos de subjetivação e, neste sentido, importanos poder traçar as circunstâncias em que eles se compuseram, que forças se atravessam e que efeitos estão se dando. 
No lugar do indivíduo, individuações. No lugar do sujeito, subjetivação. Como nos conceitos, não se trata de modo algum de reunir, unificar, mas de construir redes por ressonâncias, deixar nascer mil caminhos que nos levariam a muitos lugares.

A clínica transdisciplinar se formaria como um sistema aberto onde $o$ analista ${ }^{14}$ não apenas criaria intercessores, elementos de passagem de um território a outro, mas onde ele próprio seria um intercessor. Produzindo agenciamentos, misturando vozes, as enunciações, agora sem sujeito, nasceriam da polifonia dos regimes de signos que se atravessam. Por exemplo, uma sensação, um som, um cheiro experimentado como ato no território que define o nível de intervenção, produz interferências, ressonâncias, amplificações, mantendo o sistema em aberto para o tempo.

As histórias trazidas pelos pacientes não seriam mais apenas conectadas entre si ou com as introduzidas pelo analista, mas também interfaceadas a outros sistemas, outros regimes de signos. Isto constituiria, muitas vezes, desconexões das/nas histórias para deixar passar outros devires. A intercessão, aqui, se dá por atravessamentos desestabilizadores, produzindo sistemas separados, tornando-se difícil falar em homeostase ou tendência ao equilíbrio. É importante que se faça esta ressalva, pois não se trata do estabelecimento de sistemas interacionais, mas de diferenças que se introduzem em dimensões da subjetivação, complexificando a situação através da pressão promovida pelos movimentos de desterritorialização.

Elkaim (1994/1996) utiliza o termo assemblage para designar uma composição que se dá por atravessamentos, impossível de retornar a seus elementos iniciais. Neste caso, o que há é uma espécie de emergência na situação por composição.

Novamente, um bom exemplo seriam as sensações, os perceptos presentes nas situações clínicas que não ganham a palavra e, em sendo assim, produzem alterações/movimentações nos territórios engessados dos sintomas. Tais signos, a-significantes, podem emergir na situação, compondo desenhos num território existencial inesperado, "desequilibrado", em estado de mutação. As histórias, neste momento, parecem "perder o sentido a que habitualmente estavam ligadas". Emerge, na cena analítica, a diferença, produzindo novos efeitos-subjetividade.

A intercessão, assim, pode se dar com qualquer elemento. É o caso, inclusive, do analista. Este pode estar como intercessor quando entra no movimento de interferência das diversas linhas que vêm ora da arte, ora da política, ora da

14 O que nos interessa afirmar quando utilizamos o termo analista é justamente a posição clínico-crítica de se colocar em análise os diferentes vetores de existencialização que se apresentam na situação de intervenção. A discussão entre as diferentes correntes clínicas, psicanalíticas ou não quanto ao caráter terapêutico e/ou (psi)analítico de suas intervenções não é objeto de interesse deste trabalho. Para nós trata-se mais de acompanhar os efeitos problematizadores da intervenção clínica e menos de classificá-los considerando a distinção entre terapia e análise. filosofia, ora de outro domínio qualquer que esteja em processo de nomadização, transmutando-se em devir, sendo minoritário, rompendo-se enquanto totalidade, abandonando seus sujeitos-objetos disciplinados em prol da criação.

Tomar, enfim, em análise, os funcionamentos e seus efeitos, experimentar ao invés de conjecturar, ocupar-se dos maquinismos que insistem na produção de outros modos de existência, esquecer-se de si e de sua história e encontrar-se na criação, parecem ser algumas faces desta clínica transdiciplinar.

\section{Referências}

Bachelard, G. (1986). Le Rationalisme Appliqué. Paris: PUF. (Trabalho original publicado em 1949)

Barbier, R.A (1985) Pesquisa-Ação na instituição educativa. (E.S. Abreu, Trad.) Rio de Janeiro: Jorge Zahar. (Trabalho original publicado em 1977).

Canguilhem, G. (1978). O normal e o patológico. (M.T.R.C. Barrocas, Trad.). Rio de Janeiro: Forense. (Trabalho original publicado em 1966).

Deleuze, G. (1992). Os Intercessores. Em Deleuze, G. Conversações. (P.P. Pelbart, Trad.). Rio de Janeiro: Editora 34. (Trabalho original publicado em 1990).

Deleuze, G. \& Guattari, F. (1991). Qu'est-ce que la philosophie? Paris: Minuit.

Deleuze, G. \& Guattari, F. (1997). Devir-Intenso, Devir-Animal, Devir-Imperceptível ... (S. Rolnik, Trad.). Em Mil Platôs - v. 4 (p.11-113). São Paulo: 34 Letras. (Trabalho original publicado em 1980).

Elkaim, M. (1996). Nos limites do enfoque sistêmico em psicoterapia. Em Novos paradigmas, cultura e subjetividade (p. 204215). Porto Alegre: Artes Médicas. (Trabalho original publicado em 1994).

Fernandéz, A.M. e De Brasi, J.C. (1993). Tiempo Historico y Campo Grupal: Masas, Grupos y Instituiciones. Buenos Aires: Nueva Visión.

Foucault, M. (1990). La Psychologie de 1850 à 1950. Revue Internationale de Philosophie 44, 159-176. (Trabalho original publicado em 1957).

Guattari, F. (1972). Psychanalyse et Transversalité. Paris: Maspero.

Koffka, K. (1935). Principles of Gestalt Psychology. New York: Harcourt.

Köhler, W. (1948). Psicologia de la Forma (R.V. de Tortarolo, Trad.). Buenos Aires: Argonauta. (Trabalho original publicado em 1928).

Lacan, J. (1978) Escritos. (I. Oseki-Depré, Trad.). São Paulo: Perspectiva. (Trabalho original publicado em 1936).

Lapassade, G. (1977). Grupos, Organizações e Instituições. (H.A. A. Mesquita, Trad.). Rio de Janeiro: Francisco Alves. (Trabalho original publicado em 1974).

Latour, B. (1994). Jamais fomos modernos. (C.I. Costa, Trad.). Rio de Janeiro: Editora 34. (Trabalho original publicado em 1991).

Lewin, K. (1973). Princípios de Psicologia Topológica. (Á. Cabral, Trad.). São Paulo: Cultrix. (Trabalho original publicado em 1936). 
Lewin, K. (1975) Teoria dinâmica da personalidade. (Á. Cabral, Trad.). São Paulo: Cultrix. (Trabalho original publicado em 1935).

Macherey, P. (1993). De Canguilhem a Canguilhem passant par Foucault. Em G. Canguilhem, Philosophe, Historien des Sciences. Paris: Albin Michel.

Marcuse, H. (1968). Eros e Civilização. (Á. Cabral, Trad.). Rio de Janeiro: Zahar. (Trabalho original publicado em 1955).

Maturana, H. \& Varela, F. (1980). Autopoiesis and cognition. The realization of the living. Dordrecht: D. Reidel.

Maturana, H. \& Varela, F. (1995) A árvore do conhecimento. (J.P. Santos, Trad.). Campinas: Editorial Psy. (Trabalho original publicado em 1987).

Passos, E. (1994). Pós-naturalismo e ciência da subjetividade. Cadernos de subjetividade, 2, 67-78. Núcleo de Estudos e Pesquisas da Subjetividade. Programa de Estudos Pós-Graduados em Psicologia Clínica da PUC/SP.

Passos, E. (1995). Pensando a subjetividade com conceitos híbridos: a psicologia em interface com a filosofia e a biologia. Revista do Departamento de Psicologia da UFF, 7, 109-123.

Rodrigues, H.C. (1992). Psicanálise e Análise Institucional. Em Rodrigues, H., Benevides de Barros, R. \& Sá Leitão, M.B.
(Orgs), Grupos e Instituições em Análise. Rio de Janeiro: Rosa dos Tempos, 1992.

Rodrigues, H. C. (1994). Subjetividades em Revolta: novas análises sobre o movimento do institucionalismo francês. Dissertação de Mestrado. Universidade do Estado do Rio de Janeiro, Rio de Janeiro.

Simondon, G. (1989). L'individuation psychique et collective. Paris: Aubier.

Stengers, I. (1990). Quem tem medo da ciência? Ciências e poderes. (E.A. Ribeiro, Trad.) São Paulo: Siciliano. (Trabalho original publicado em 1989).

Stengers, I. (1993). L'invention des sciences modernes. Paris: Découverte.

Thiollent, M. (1987) Crítica metodológica, investigação social. São Paulo: Polis.

Turkle, S. (1981). Psychoanalytic Politics. Freud's French revolution. Cambridge, Massachusetts: MIT Press.

Varela, F. (1995). Sobre a competência ética. (A. Morão, Trad.). Lisboa: Edições 70. (Trabalho original publicado em 1992).

Watzlawick, P. (1994). A realidade inventada. (J.P. Santos, Trad.). Campinas: Editorial Psy II. (Trabalho original publicado em 1981).

\section{MUDANÇA DE ENDEREÇO}

Se você está mudando de endereço por favor notifique $P s i$ cologia: Teoria e Pesquisa. Ocasionalmente, assinantes e autores comunicam tardiamente mudança de endereço determinando dificuldades na entrega de nossa revista ou de outras correspondências. Informe imediatamente, se possível com antecedência, qualquer mudança de domicílio para:

Universidade de Brasília - Instituto de Psicologia

Revista Psicologia: Teoria e Pesquisa

Secretaria de Divulgação

70910-900 Brasília DF

Mudanças de endereço poderão também ser comunicadas através do correio eletrônico revptp@unb.br ou do telefone e fax (061) 274-6455. 